\title{
The Surviving Sepsis Campaign: results of an international guideline-based performance improvement program targeting severe sepsis
}

\section{Citation}

Levy, Mitchell M., R. Phillip Dellinger, Sean R. Townsend, Walter T. Linde-Zwirble, John C. Marshall, Julian Bion, Christa Schorr, et al. 2010. The Surviving Sepsis Campaign: results of an international guideline-based performance improvement program targeting severe sepsis. Intensive Care Medicine 36(2): 222-231.

\section{Published Version}

doi:10.1007/s00134-009-1738-3

\section{Permanent link}

http://nrs.harvard.edu/urn-3:HUL.InstRepos:4874821

\section{Terms of Use}

This article was downloaded from Harvard University's DASH repository, and is made available under the terms and conditions applicable to Other Posted Material, as set forth at http:// nrs.harvard.edu/urn-3:HUL.InstRepos:dash.current.terms-of-use\#LAA

\section{Share Your Story}

The Harvard community has made this article openly available.

Please share how this access benefits you. Submit a story.

Accessibility 
Mitchell M. Levy

R. Phillip Dellinger

Sean R. Townsend

Walter T. Linde-Zwirble

John C. Marshall

Julian Bion

Christa Schorr

Antonio Artigas

Graham Ramsay

Richard Beale

Margaret M. Parker

Herwig Gerlach

Konrad Reinhart

Eliezer Silva

Maurene Harvey

Susan Regan

Derek C. Angus

Received: 26 May 2009

Accepted: 27 November 2009

Published online: 13 January 2010

(C) Copyright jointly hold by Springer and ESICM 2010

On behalf of the Surviving Sepsis

Campaign.

This article is being simultaneously

published in Intensive Care Medicine and Critical Care Medicine.

This article is discussed in the editorial available at:

doi:10.1007/s00134-009-1737-4.

Electronic supplementary material The online version of this article

(doi:10.1007/s00134-009-1738-3) contains supplementary material, which is available to authorized users.

M. M. Levy (®)

Division of Pulmonary, Sleep and Critical Care Medicine, Brown University School of Medicine, Rhode Island Hospital, 593 Eddy St., Providence, RI 02903, USA e-mail: Mitchell_Levy@brown.edu

\section{R. P. Dellinger · C. Schorr}

Department of Medicine, University of Medicine and Dentistry of New Jersey, Cooper University Hospital,

Camden, NJ, USA

\section{The Surviving Sepsis Campaign: results of an international guideline-based performance improvement program targeting severe sepsis}

S. R. Townsend

Division of Pulmonary, Allergy, and Critical Care Medicine,

University of Massachusetts Medical

School, Worcester, MA, USA

\section{S. R. Townsend}

The Institute for Healthcare Improvement, Cambridge, MA, USA

W. T. Linde-Zwirble

ZD Associates LLC,

Perkasie, PA, USA

J. C. Marshall

Department of Surgery,

Li Ka Shing Knowledge Institute,

St. Michael's Hospital, University

of Toronto, Toronto, ON, Canada

\section{J. Bion}

University Department of Anaesthesia and Intensive Care Medicine,

Queen Elizabeth Hospital,

Edgbaston, Birmingham, UK

\section{A. Artigas}

Critical Care Centre, Sabadell Hospital, CIBER Enfermedades Respiratorias,

Autonomous University of Barcelona,

Barcelona, Spain

G. Ramsay

Mid Essex Hospital Services NHS Trust, London, UK

R. Beale

Guy's and St. Thomas'

NHS Foundation Trust, St. Thomas'

Hospital, London, UK
M. M. Parker

Department of Medicine, Stony Brook University, Stony Brook, NY, USA

H. Gerlach

Vivantes-Klinikum Neukoelln,

Berlin, Germany

K. Reinhart

Clinic for Anesthesiology and Intensive

Care, Jena, Germany

E. Silva

Hospital Israelita Albert Einstein,

Sao Paolo, Brazil

\section{Harvey}

Consultants in Critical Care, Inc.,

Glenbrook, NV, USA

\section{S. Regan}

Department of Medicine, Harvard Medical School and General Medicine Division, Massachusetts General Hospital,

Boston, MA, USA

D. C. Angus

CRISMA Laboratory,

Department of Critical Care Medicine,

University of Pittsburgh,

Pittsburgh, PA, USA
Abstract Objective: The Surviv- ing Sepsis Campaign (SSC or "the Campaign") developed guidelines for management of severe sepsis and septic shock. A performance improvement initiative targeted 
changing clinical behavior (process improvement) via bundles based on key SSC guideline recommendations on process improvement and patient outcomes. Design and setting: A multifaceted intervention to facilitate compliance with selected guideline recommendations in the ICU, ED, and wards of individual hospitals and regional hospital networks was implemented voluntarily in the US, Europe, and South America. Elements of the guidelines were "bundled" into two sets of targets to be completed within $6 \mathrm{~h}$ and within $24 \mathrm{~h}$. An analysis was conducted on data submitted from January 2005 through March 2008. Main results: Data from 15,022 subjects at 165 sites were analyzed to determine the compliance with bundle targets and association with hospital mortality. Compliance with the entire resuscitation bundle increased linearly from $10.9 \%$ in the first site quarter to $31.3 \%$ by the end of 2 years $(P<0.0001)$. Compliance with the entire management bundle started at $18.4 \%$ in the first quarter and increased to $36.1 \%$ by the end of 2 years $(P=0.008)$. Compliance with all bundle elements increased significantly, except for inspiratory plateau pressure, which was high at baseline. Unadjusted hospital mortality decreased from 37 to $30.8 \%$ over 2 years $(P=0.001)$. The adjusted odds ratio for mortality improved the longer a site was in the Campaign, resulting in an adjusted absolute drop of $0.8 \%$ per quarter and $5.4 \%$ over 2 years (95\% CI, 2.5-8.4\%). Conclusions: The Campaign was associated with sustained, continuous quality improvement in sepsis care. Although not necessarily cause and effect, a reduction in reported hospital mortality rates was associated with participation. The implications of this study may serve as an impetus for similar improvement efforts.

Keywords Severe sepsis . Septic shock - Knowledge transfer . Performance measures - Surviving sepsis campaign - Performance improvement - Sepsis bundles . Quality improvement

\section{Introduction}

Severe sepsis accounts for $20 \%$ of all admissions to intensive care units (ICUs) and is the leading cause of death in non-cardiac ICUs, yet comprehensive clinical practice guidelines had not existed [1, 2]. In 2002, hopeful that outcomes of sepsis might be improved by standardizing care and informed by data from an increasing number of clinical trials [3-10], the European Society of Intensive Care Medicine (ESICM), the International Sepsis Forum (ISF), and the Society of Critical Care Medicine (SCCM) launched the Surviving Sepsis Campaign (SSC or "the Campaign") [11]. Evidence-based guidelines were developed through a formal and transparent process [12-14]. The initial guidelines were published in 2004 (endorsed by 11 professional societies); an updated version was published in 2008 (involving 18 organizations comprising professional societies and organized networks of hospitals).

The development and publication of guidelines often do not lead to changes in clinical behavior and guidelines are rarely, if ever, integrated into bedside practice in a timely fashion [15-20]. The most effective means for achieving knowledge transfer remains an unanswered question across all medical disciplines [21, 22]. Recognizing that implementing guidelines presents a significant challenge, the Campaign set out to develop and evaluate a multifaceted model to change bedside practice to be consistent with the recently published management guidelines for patients with severe sepsis and septic shock. A central part of that program was an international registry into which providers could recruit and enter patients and monitor their institution's performance. This analysis of the registry data describes the global initiative, its implementation, and reports its impact on process improvement and patient outcomes.

\section{Methods}

The SSC performance improvement initiative was launched in multiple sites internationally to measure changes in the rates at which the sites achieved the targets of the guideline bundles and to assess the impact of compliance with the program on hospital mortality. The Campaign activities included: the development of sepsis bundles; creation of educational materials; recruitment of sites and local physician and nurse champions through national and international meetings; organization of regional launch meetings where the initiative was introduced and educational materials presented; and the distribution of a secure database application that allowed for data collection and transfer, and offered a simple means for providing practice audit and feedback to local clinicians.

\section{Guideline and bundle development}

After the development of the evidence-based guidelines, the SSC steering committee partnered with the Institute for Healthcare Improvement (IHI) to develop a quality improvement program to extend the Campaign guidelines to the bedside management of severely septic and septic shock patients [23, 24]. In partnership with IHI, key elements of the guidelines were identified and organized 
Fig. 1 Resuscitation and management bundles as provided for Campaign participants' use

\author{
Severe Sepsis Bundles: \\ Sepsis Resuscitation Bundle \\ (To be accomplished as soon as possible and scored over first 6 hours): \\ 1. Serum lactate measured. \\ 2. Blood cultures obtained prior to antibiotic administration. \\ 3. From the time of presentation, broad-spectrum antibiotics administered within 3 hours for ED admissions and 1 hour for \\ non-ED ICU admissions. \\ 4. In the event of hypotension and/or lactate $>4 \mathrm{mmol} / \mathrm{L}(36 \mathrm{mg} / \mathrm{dl})$ : a) Deliver an initial minimum of $20 \mathrm{ml} / \mathrm{kg}$ of crystalloid \\ (or colloid equivalent). b) Apply vasopressors for hypotension not responding to initial fluid resuscitation to \\ maintain mean arterial pressure (MAP) $>65 \mathrm{~mm} \mathrm{Hg}$ \\ 5. In the event of persistent hypotension despite fluid resuscitation (septic shock) and/or lactate $>4 \mathrm{mmol} / \mathrm{L}$ ( $36 \mathrm{mg} / \mathrm{dl}$ ): \\ a) Achieve central venous pressure (CVP) of $>8 \mathrm{~mm} \mathrm{Hg}$. \\ b) Achieve central venous oxygen saturation $\left(\mathrm{ScvO}_{2}\right)$ of $>70 \%$.* \\ Sepsis Management Bundle \\ (To be accomplished as soon as possible and scored over first $\mathbf{2 4}$ hours): \\ 1 Low-dose steroids administered for septic shock in accordance with a standardized hospital policy. \\ 2 Drotrecogin alfa (activated) administered in accordance with a standardized hospital policy. \\ 3 Glucose control maintained > lower limit of normal, but $<150 \mathrm{mg} / \mathrm{dl}(8.3 \mathrm{mmol} / \mathrm{L})$. \\ 4 Inspiratory plateau pressures maintained $<30 \mathrm{~cm} \mathrm{H} \mathrm{H}_{2} \mathrm{O}$ for mechanically ventilated patients. \\ ${ }^{*}$ Achieving a mixed venous oxygen saturation $\left(\mathrm{SvO}_{2}\right)$ of $65 \%$ is an acceptable alternative. \\ (C) 2005 Surviving Sepsis Campaign and the Institute for Healthcare Improvement
}

into "bundles" of care $[25,26]$. A two-phase approach was established, which included the generation of two sets of performance measures: the first to be accomplished within $6 \mathrm{~h}$ of presentation with severe sepsis (the "resuscitation bundle") and a second set to be accomplished within $24 \mathrm{~h}$ (the "management bundle") (Fig. 1) [27, 28].

Sites and patient selection

Any hospital wishing to join the Campaign was eligible. Participation was voluntary. Participant sites were recruited at professional critical care congresses and meetings, through the SSC and IHI Web sites, and by interest generated from publication of the SSC guidelines. Campaign symposia were regularly held at international congresses and other venues between 2004 and 2008 to increase awareness and participation. Local champions and Campaign faculty were identified and trained to develop regional and national networks.

Sites were encouraged to set up screening procedures to identify patients with severe sepsis based on previously established criteria [29]. Sites were provided a sample screening tool in the Campaign manual and on the Web site [30]. Participating sites were asked to screen for patients in the emergency department (ED), the clinical wards, and the ICU. Methods of screening were ultimately established locally, and no effort to supervise the quality or completeness of screening was attempted.

To be enrolled, a subject had to have a suspected site of infection, two or more systemic inflammatory response syndrome (SIRS) criteria [29], and one or more organ dysfunction criteria. (See Supplemental Fig. 1 online.) Clinical and demographic characteristics and time of presentation with severe sepsis criteria were collected for analysis of time-based measures. Time of presentation was determined through chart review and defined in instructions to site data collectors on the Campaign Web site and educational materials. For patients enrolled from the ED, the time of presentation was defined as the time of triage. For patients admitted to the ICU from the medical and surgical wards and for patients in the ICU at the time of diagnosis, the time of presentation was determined by chart review for the diagnosis of severe sepsis.

Educational materials and resources

Educational materials available on the SSC Web site included directions for implementing the bundles and supporting data for each bundle element. A comprehensive manual, Implementing the Surviving Sepsis Campaign, was published in 2005 and included the data collection tool in CD format [30]. The manual was also distributed at meetings. It included protocols for participation and links to download the database. It also reviewed issues related to ensuring consistency and quality in data collection. The manual contents were placed on the IHI and SSC Web sites. Cards and posters of the two sepsis bundles (Fig. 1) were printed and widely distributed.

During the course of the study period, initiation meetings were held for participating hospital groups and regional SSC launches, at which educational materials were distributed, methods for data collection described, institutional change concepts introduced, and examples of implementation discussed. Ultimately, hospital-level efforts and local protocol development were the purview of individual improvement teams at each institution or network. An e-mail list server with voluntary membership was established to allow teams to collaborate across sites by asking questions of their colleagues and to direct communication from the SSC to sites. List members were encouraged to share tools, protocols, and experiences. Although no formal evaluation was in place to assess the 
quality of data entered, concern regarding this topic was the second most frequently discussed area among participants (following concern regarding roadblocks to achieving physician engagement). Two of the authors (CS and SRT) served as primary references for all questions regarding data collection and entry throughout the Campaign, and provided training for each site when requested. A bi-monthly electronic newsletter was published to share successes, strategies, and events.

\section{Bundle targets and clinical outcomes}

The primary outcome measure was change in compliance with bundle targets over time. We defined compliance as evidence that all bundle elements were achieved within the indicated time frame (i.e, $6 \mathrm{~h}$ for the resuscitation bundle; $24 \mathrm{~h}$ for the management bundle). As such, failure to comply might occur either because of the failure of the physician to attempt to meet the target or the failure to reach the target despite the clinician's attempt. Secondary outcome measures included hospital mortality, hospital length of stay, and ICU length of stay. Ten performance measures were established, based on the individual elements of the resuscitation bundle and the management bundle.

\section{Data collection}

Data were entered into the SSC database locally at individual hospitals into pre-established, unmodifiable fields documenting performance data and the time of specific actions and findings. Data on the local database contained private health information (PHI) that enabled individual sites to audit and review local practice and compliance as well as provide feedback to clinicians involved in the initiative. Data stripped of PHI were submitted every 30 days to the secure master SSC server at the Society of Critical Care Medicine (Mount Prospect, Ill.) via file transfer protocol (FTP) or as comma-delimited text files attached to e-mail submitted to the Campaign's server.

\section{IRB approval}

The global SSC improvement initiative was reviewed and approved by the Cooper University Hospital Institutional Review Board (Camden, NJ) as meeting criteria for exempt status. Individual hospitals were encouraged to refer to these documents and submit to their local IRBs per local policy for documentation of exempt status or waiver of consent. The US Department of Health and Human Services' Office for Human Research Protections clarified that quality improvement activities such as SSC often qualify for IRB exemption and do not require individual informed consent [31].
Table 1 Inclusion in database by quarter

\begin{tabular}{lcc}
\hline Quarter & Patients & Sites \\
\hline 1 & 2,791 & 165 \\
2 & 2,709 & 160 \\
3 & 2,945 & 153 \\
4 & 1,945 & 123 \\
5 & 1,435 & 76 \\
6 & 935 & 54 \\
7 & 940 & 57 \\
8 & 509 & 34 \\
\hline
\end{tabular}

\section{Analysis set construction}

The analysis set was constructed from the subjects entered into the SSC database from its launch in January 2005 through March 2008. The a priori data analysis plan limited inclusion to sites with at least 20 subjects and at least 3 months of subject enrollment. Analysis presented here was limited to the first 2 years of subjects at each site (Table 1).

Sites were characterized by: hospital size $(<250,250$ $500,>500$ beds); teaching status; ICU type (medical, medical/surgical, other); and geographic region (Europe, North America, South America). Subjects were characterized by baseline severe sepsis information: location of enrollment (ED, ICU, ward); site of infection (pulmonary, urinary tract, abdominal, CNS, skin, bone, wound, catheter, cardiac, device, other); acute organ dysfunction (cardiovascular, pulmonary, renal, hepatic, hematologic). Subject age and gender were not collected in deference to country-specific privacy laws.

Data were organized by quarter through 2 years, with the first 3 months that a site entered subjects into the database defined as the first quarter regardless of when those months occurred from January 2005 through March 2008. Results are presented by site quarter, comparing the initial quarter to the final quarter for all sites and by comparing the initial quarter to all subsequent quarters.

Because differences in bundle achievement and outcomes could be confounded by changes in the characteristics of subjects entered into the database, riskadjustment logistic regression models were constructed to control for baseline subject characteristics. All baseline characteristics present in the database were included in the risk-adjustment models including location of enrollment, acute organ dysfunctions, and site of infection. Site of infection was reduced to pulmonary or non-pulmonary to decrease the number of covariate patterns in the data and increase the utility of the model residuals to assess model fit. Because the collection of some bundle elements was conditioned on subject characteristics, different models were constructed for each subpopulation. The model assessing the base set of elements applicable to all subjects (lactate measurement, blood culture before antibiotic administration, broad spectrum antibiotic administration, 
and glucose control) included the baseline subject characteristics as well as these elements. The model assessing the administration of drotrecogin alfa in subjects with multiple organ failures also included the baseline subject characteristics and the base set of bundle elements. The model assessing plateau pressure control in mechanically ventilated subjects also included the baseline subject characteristics and the base set of bundle elements. The model assessing the administration of drotrecogin alfa, low-dose steroids, $\mathrm{CVP}>8$, and $\mathrm{ScvO}_{2}>70$ in subjects in shock despite fluids also included the baseline subject characteristics and the base set of bundle elements.

To demonstrate that a decrease in hospital mortality over time was not associated with entering less severely ill patients in the database at individual sites, a logistic regression model was constructed. It contained all subjects entered over the maximum of 2 years of data collection and the baseline subject characteristics for the quarter of participation for up to eight quarters. Because sites could enter the Campaign at any time, the possibility that decreased hospital mortality over time was associated with a global decrease in mortality for the same severity of illness was investigated by constructing a logistic regression model for hospital mortality using the first quarter of data collection from each site, including the baseline subject characteristics and the calendar quarter (1 for the first quarter of 2005 through 13 for the first quarter of 2008).

\section{Statistical analysis}

We compared raw rates including hospital mortality and bundle compliance using Fisher's exact test. We expressed the effects of predictor variables on hospital mortality using odds ratios, including $95 \%$ confidence intervals for risk-adjusted results. We assessed logistic regression model fit using the Hosmer-Lemeshow $C$ statistic, the $\chi^{2}$ dispersion, the proportion of log-likelihood accounted for by the model, and an examination of model residuals. We constructed the databases in Access and FoxPro (Microsoft Corp., Redmond, WA) and conducted analyses in DataDesk (Data Description, Ithaca, NY) and SAS (SAS Institute, Cary, NC).

\section{Results}

Between January 2005 and March 2008, 15,775 subjects at 252 qualifying sites were entered into the SSC database (see Supplemental Table 1 online). Excluding hospitals that contributed fewer than 20 subjects, the final sample consisted of 15,022 patients at 165 hospitals (a median of 57 and range of 20-471 subjects per hospital). Data from up to eight quarters were analyzed from each site.
Hospitals contributed data for a mean duration of 15.6 months (median of 14 months). Table 2 includes site and patient characteristics.

\section{Change in achievement of bundle targets over time}

Compliance rates for achieving all bundle targets over time-both the overall bundles and the individual elements within both bundles-increased over time, although both basal achievement rates and the magnitude of improvement varied considerably across targets (Table 3). Compliance with the initial 6-h bundle targets increased linearly from $10.9 \%$ of subjects in the first site quarter to $31.3 \%$ by the end of 2 years in the campaign, achieving statistical significance by the second quarter (10.9 vs. $14.9 \%, P<0.0001$ ) (Fig. 2). The ability to achieve the entire 24-h management bundle targets started higher, at $18.4 \%$ in the first quarter, and increased to $36.1 \%$ by the end of 2 years, but did not achieve statistical significance until the fourth quarter (18.4 vs. $21.5 \%$, $P=0.008)$.

\section{Changes in hospital mortality}

Unadjusted hospital mortality decreased from $37.0 \%$ in the first quarter in the Campaign to $30.8 \%$ by 2 years $(P=0.001)$. On average, unadjusted mortality decreased by $0.91 \%$ (95\% CI $0.42-1.40 \%$ ) for each quarter in the Campaign. The results of the multivariable model examining the effect of time in the Campaign on hospital mortality are summarized in Table 4 . The model fit well (Hosmer and Lemeshow $C$ statistic of 18.1 with 18 degrees of freedom, $P=0.34$ accounted for $36.6 \%$ of variation in the data, with a $\chi^{2}$ dispersion of 1.04). In both the unadjusted and adjusted models, the chance of death decreased the longer a site was in the Campaign, resulting in an adjusted absolute drop of $0.8 \%$ per quarter and $5.4 \%$ over the first 2 years $(95 \%$ CI, 2.5-8.4\%). In contrast, the model examining the first quarter of data from all sites did not find a secular trend, associated with calendar time, to be significantly associated with mortality $(P=0.23)$. The model fit well (Hosmer and Lemeshow $C$ statistic of 16.6 with 18 degrees of freedom, $P=0.55$, accounted for $18.4 \%$ of variation in the data, with a $\chi^{2}$ dispersion of $1.05)$.

Relationship between bundle targets and hospital mortality

After adjustment for baseline characteristics, administration of broad-spectrum antibiotics (OR 0.86, 95\% CI $0.79-0.93, P<0.0001$ ), obtaining blood cultures before their initiation (OR 0.76, 95\% CI $0.70-0.83, P<0.0001$ ), 
Table 2 Cohort characteristics

\begin{tabular}{|c|c|c|}
\hline Site characteristics & $\begin{array}{l}\text { Subjects }(\%) \\
N=15,022\end{array}$ & $\begin{array}{l}\text { Sites }(\%) \\
N=165\end{array}$ \\
\hline \multicolumn{3}{|l|}{ Hospital size } \\
\hline$<250$ beds & 9.9 & 19.3 \\
\hline $250-500$ beds & 42.3 & 39.8 \\
\hline$>500$ beds & 47.8 & 40.9 \\
\hline \multicolumn{3}{|l|}{ Teaching status } \\
\hline Teaching & 69.2 & 69.3 \\
\hline Non-teaching & 30.8 & 30.7 \\
\hline \multicolumn{3}{|l|}{ ICU Type } \\
\hline Medical & 23.3 & 17.0 \\
\hline Medical/surgical & 71.3 & 78.4 \\
\hline Other & 5.4 & 4.6 \\
\hline \multicolumn{3}{|l|}{ Region } \\
\hline Europe & 31.1 & 41.0 \\
\hline North America & 58.9 & 47.0 \\
\hline South America & 10.0 & 12.0 \\
\hline Patient characteristics & $\begin{array}{l}\text { Subjects } \\
(\%)\end{array}$ & $\begin{array}{l}\text { Hospital } \\
\text { mortality }(\%)\end{array}$ \\
\hline \multirow{2}{*}{\multicolumn{3}{|c|}{ All }} \\
\hline & & \\
\hline $\mathrm{ED}$ & 52.4 & 27.6 \\
\hline ICU & 12.8 & 41.3 \\
\hline Ward & 34.8 & 46.8 \\
\hline \multicolumn{3}{|l|}{ Site of infection } \\
\hline Pneumonia & 44.4 & 38.2 \\
\hline UTI & 20.8 & 25.1 \\
\hline Abdominal & 21.1 & 40.8 \\
\hline Meningitis & 1.6 & 23.0 \\
\hline Skin & 5.9 & 28.6 \\
\hline Bone & 1.2 & 31.9 \\
\hline Wound & 3.8 & 32.2 \\
\hline Catheter & 4.1 & 33.9 \\
\hline Endocarditis & 1.1 & 41.0 \\
\hline Device & 1.1 & 42.5 \\
\hline Other infection & 12.7 & 33.1 \\
\hline \multicolumn{3}{|l|}{ Baseline acute organ dysfunctions } \\
\hline Cardiovascular $^{\mathrm{a}}$ & 85.6 & 35.4 \\
\hline Pulmonary ${ }^{\mathrm{b}}$ & 30.8 & 41.5 \\
\hline $\operatorname{Rena}^{\mathrm{b}}$ & 39.5 & 40.5 \\
\hline Hepatic $^{\mathrm{b}}$ & 10.2 & 45.1 \\
\hline Hematologic $^{\mathrm{b}}$ & 25.7 & 45.0 \\
\hline \multicolumn{3}{|l|}{$\begin{array}{l}\text { Number of acute organ } \\
\text { dysfunctions }\end{array}$} \\
\hline 1 & 41.8 & 27.4 \\
\hline 2 & 32.2 & 34.4 \\
\hline 3 & 17.8 & 43.7 \\
\hline 4 & 6.4 & 52.5 \\
\hline 5 & 1.8 & 63.6 \\
\hline \multicolumn{3}{|l|}{ Cardiovascular } \\
\hline No cardiovascular dysfunction & 13.5 & 31.0 \\
\hline $\begin{array}{l}\text { Cardiovascular dysfunction no } \\
\text { hypotension }\end{array}$ & 15.0 & 21.2 \\
\hline \multicolumn{3}{|l|}{ Shock } \\
\hline Lactate $>4$ only & 5.4 & 29.9 \\
\hline Vasopressors only & 49.5 & 36.7 \\
\hline Lactate $>4$ and vasopressors & 16.6 & 46.1 \\
\hline Total shock & 71.5 & 38.4 \\
\hline
\end{tabular}

and maintaining blood glucose control (OR $0.67,95 \% \mathrm{CI}$ $0.62-0.71, P<0.0001)$ were all associated with lower hospital mortality. Measuring lactate was not associated with improved outcome (OR 0.97, 95\% CI 0.90-1.05, $P=0.48$ ) (Table 5). The administration of drotrecogin alfa in the first $24 \mathrm{~h}$ was associated with improved survival in those with shock (OR $0.81,95 \%$ CI $0.68-0.96$, $P=0.02$ ). For those who required mechanical ventilation, achieving plateau pressure control was associated with improved outcome (OR 0.70, 95\% CI 0.62-0.78, $P<0.0001)$. In those with septic shock, there was no association between mortality and the use of low-dose steroids, the ability to achieve a CVP $\geq 8 \mathrm{mmHg}$, or demonstration of $\mathrm{ScvO} 2 \geq 70 \%$.

\section{Discussion}

The Surviving Sepsis Campaign-a performance improvement effort by hospitals across Europe, South America, and the US-recruited the largest prospective series of severe sepsis patients yet studied. The effort took place in 30 countries, was voluntary (no sites or clinicians were paid for data collection or for becoming part of the Campaign), and was multidisciplinary, reflecting the ethos of the founding professional societies. By instituting a practice improvement program grounded in evidencebased guidelines, SSC increased compliance with the change bundles that was associated with better patient outcomes. These results are consistent with other published studies that established the impact of performance "bundles" on outcomes [32-35].

SSC was a performance improvement process, and not a dedicated scientific evaluation of the impact of the guidelines on clinical outcome. Efficacy was inferred by observation of change over time, rather than through the more rigorous approach of a randomized controlled trial. Thus, conclusions regarding the clinical impact of bundle elements, or even of the process itself, must be interpreted with caution. The observation that early detection of infection and institution of antibiotic therapy led to improved survival is consistent with both empirical data [36] and generally held professional opinion. On the other hand, the observation that achievement of glucose control is associated with better outcome is not necessarily supported by recent RCT data [37].

Certain limitations must be considered in interpreting these findings. Participation in the process was entirely voluntary. The hospitals themselves are not necessarily representative of hospitals that did not participate, and the generalizability of our findings is, therefore, speculative. Further, we do not know whether the patients were a comprehensive or representative sample of all potentially 
Table 3 Change in achievement of bundle targets

\begin{tabular}{|c|c|c|c|c|c|}
\hline & $\begin{array}{l}\text { Initial quarter } \\
\text { achieved }(\%)\end{array}$ & $\begin{array}{l}\text { Final quarter } \\
\text { achieved }(\%)^{\mathrm{a}}\end{array}$ & $\begin{array}{l}P \text { value } \\
\text { compared } \\
\text { to initial }\end{array}$ & $\begin{array}{l}\text { Remaining } \\
\text { quarters } \\
\text { achieved }(\%)\end{array}$ & $\begin{array}{l}P \text { value } \\
\text { compared } \\
\text { to initial }\end{array}$ \\
\hline \multicolumn{6}{|l|}{ Initial care bundle (first $6 \mathrm{~h}$ of presentation) } \\
\hline Measure lactate & 61.0 & 78.7 & $\leq 0.0001$ & 72.5 & $\leq 0.0001$ \\
\hline Blood cultures before antibiotics & 64.5 & 78.3 & $\leq 0.0001$ & 76.3 & $\leq 0.0001$ \\
\hline Broad spectrum antibiotics & 60.4 & 67.9 & 0.0002 & 67.0 & $\leq 0.0001$ \\
\hline Fluids and vasopressors & 59.8 & 77.0 & $\leq 0.0001$ & 71.1 & $\leq 0.0001$ \\
\hline $\mathrm{CVP}>8 \mathrm{mmHg}$ & 26.3 & 38.0 & $\leq 0.0001$ & 33.9 & $\leq 0.0001$ \\
\hline $\mathrm{ScvO} 2>70 \%$ & 13.3 & 24.3 & $\leq 0.0001$ & 21.7 & $\leq 0.0001$ \\
\hline All resuscitation measures & 10.9 & 21.5 & $\leq 0.0001$ & 21.1 & $\leq 0.0001$ \\
\hline \multicolumn{6}{|c|}{ Management bundle (first $24 \mathrm{~h}$ after presentation) } \\
\hline Steroid policy & 58.5 & 73.9 & $\leq 0.0001$ & 66.8 & $\leq 0.0001$ \\
\hline Administration of drotrecogin alfa policy & 47.4 & 53.5 & 0.003 & 49.9 & 0.02 \\
\hline Glucose control & 51.4 & 56.8 & 0.0009 & 55.4 & $\leq 0.0001$ \\
\hline Plateau pressure control & 80.8 & 83.8 & 0.24 & 82.6 & 0.09 \\
\hline All management measures & 18.4 & 25.5 & $\leq 0.0001$ & 23.3 & $\leq 0.0001$ \\
\hline
\end{tabular}

${ }^{a}$ Represents the last quarter of data submission from each institution during the 2-year data analysis period, regardless of total number of quarters of each institution's participation
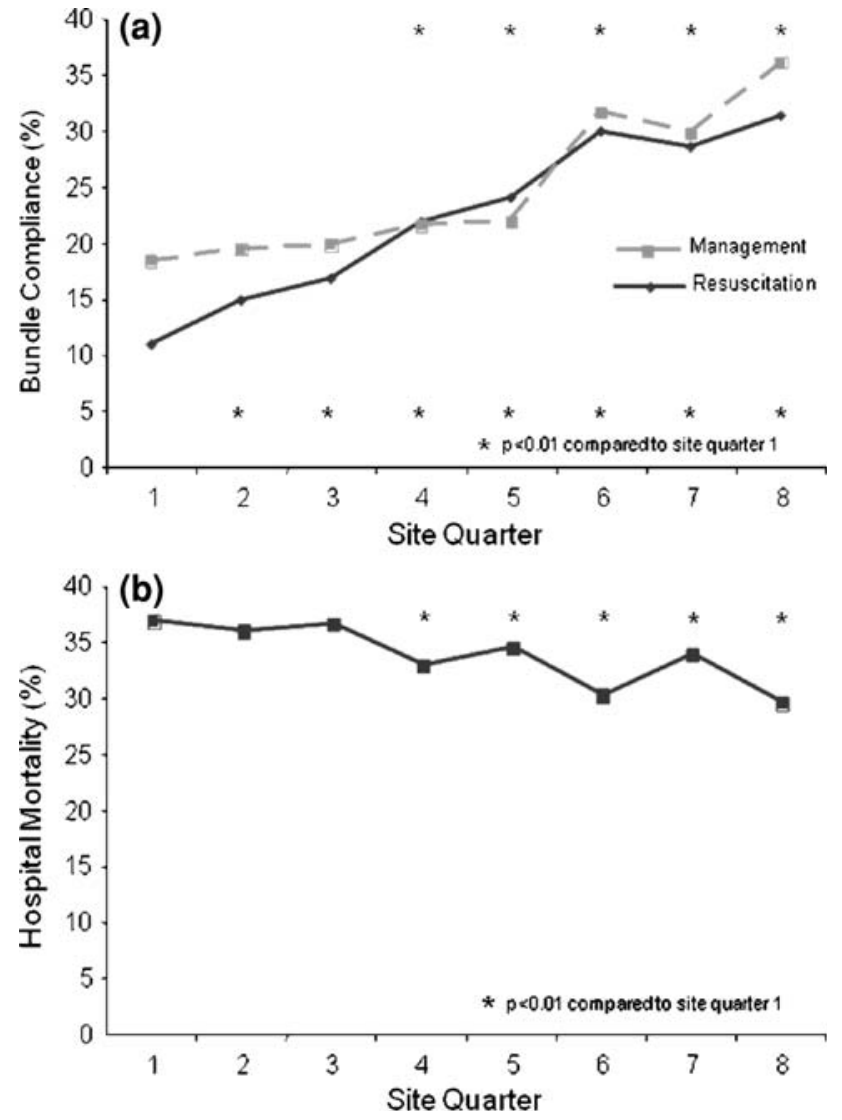

Fig. 2 Compliance and mortality change over time: a change in the percentage of patients compliant with all elements of the resuscitation bundle (dotted line) and the management bundle (solid line) over 2 years of data collection $(* P<0.01$ compared to first quarter). Note that both $Y$ axes are truncated at $40 \%$ to emphasize relative change over time as opposed to absolute change; $\mathbf{b}$ change in hospital mortality over time $(* P<0.01$ compared to first quarter)
Table 4 Multivariable mortality prediction model

\begin{tabular}{llll}
\hline Variable & OR & $95 \%$ CI & $P$ value \\
\hline Admission source & & & \\
$\quad$ Ward compared to ED & 1.87 & {$[1.73,2.02]$} & $\leq 0.0001$ \\
ICU compared to ED & 2.25 & {$[2.02,2.51]$} & \\
$\begin{array}{l}\text { Pneumonia as source of sepsis } \\
\quad 1.37\end{array}$ & {$[1.27,1.48]$} & $\leq 0.0001$ \\
$\quad$ compared to other infections & & & \\
$\begin{array}{l}\text { Organ dysfunction at presentation } \\
\quad \text { Cardiovascular }\end{array}$ & 1.39 & {$[1.26,1.55]$} & $\leq 0.0001$ \\
Respiratory & 1.23 & {$[1.14,1.34]$} & $\leq 0.0001$ \\
Hematologic & 1.61 & {$[1.48,1.75]$} & $\leq 0.0001$ \\
Hepatic & 1.28 & {$[1.14,1.75]$} & $\leq 0.0001$ \\
$\quad$ Renal & 1.40 & {$[1.30,1.51]$} & $\leq 0.0001$ \\
Site duration in campaign & & & \\
$\quad$ Per quarter & 0.97 & {$[0.96,0.99]$} & 0.0006 \\
\hline
\end{tabular}

Model fit statistics: $C=18.1$ with $18 d f, P=0.34$, log-likelihood $R^{2}$ sq $36.6 \%$, a $\chi^{2}$ dispersion of 1.04

eligible subjects at each site. Sites with varying lengths of participation are included in the analysis. While the rate of enrollment over time was relatively constant for each site, the possibility that the types of patients selected changed over time cannot be excluded. We believe the data are encouraging and supportive of the Campaign's creating beneficial effects both on patient care and patient outcome. Because the bundles combine physiologic endpoints and processes of care, measures of compliance may not be precise. However, the improvement in measures over time probably reflects improving compliance, assuming the case mix was reasonably stable. The independent association of these bundle targets with outcome does not necessarily imply a causal relationship between the bundle care recommendation and outcomes. Failure to achieve a target may be indicative of greater severity, so compliance with the attempt alone may produce the false impression that compliance is associated with reduced 
Table 5 Risk-adjusted impact of bundle targets on hospital mortality

\begin{tabular}{|c|c|c|c|c|c|c|c|}
\hline \multirow[t]{2}{*}{ Bundle target } & \multirow[t]{2}{*}{ Population } & \multirow[t]{2}{*}{$N$} & \multicolumn{2}{|c|}{ Unadjusted } & \multicolumn{3}{|c|}{ Risk-adjusted } \\
\hline & & & OR & $P$ value & OR & $95 \% \mathrm{CI}$ & $P$ value \\
\hline Measure lactate & $\mathrm{All}^{\mathrm{a}}$ & 15,022 & 0.86 & $<0.0001$ & 0.97 & {$[0.90,1.05]$} & 0.48 \\
\hline Obtain blood cultures before antibiotics & $\mathrm{All}^{\mathrm{a}}$ & 15,022 & 0.70 & $<0.0001$ & 0.76 & {$[0.70,0.83]$} & $<0.0001$ \\
\hline Commence broad-spectrum antibiotics & $\mathrm{All}^{\mathrm{a}}$ & 15,022 & 0.78 & $<0.0001$ & 0.86 & {$[0.79,0.93]$} & $<0.0001$ \\
\hline Achieve tight glucose control & $\mathrm{All}^{\mathrm{a}}$ & 15,022 & 0.65 & $<0.0001$ & 0.67 & {$[0.62,0.71]$} & $<0.0001$ \\
\hline Administer drotrecogin alfa & Multi-organ failure ${ }^{\mathrm{b}}$ & 8,733 & 0.90 & 0.26 & 0.84 & {$[0.69,1.02]$} & 0.07 \\
\hline Administer drotrecogin alfa & Shock despite fluids ${ }^{c}$ & 7,854 & 0.91 & 0.30 & 0.81 & {$[0.68,0.96]$} & 0.02 \\
\hline Administer low-dose steroids & Shock despite fluids ${ }^{\mathrm{c}}$ & 7,854 & 1.06 & 0.18 & 1.06 & {$[0.96,1.17]$} & 0.24 \\
\hline Demonstrate CVP $\geq 8 \mathrm{mmHg}$ & Shock despite fluids ${ }^{\mathrm{c}}$ & 7,854 & 1.08 & 0.10 & 1.00 & {$[0.89,1.12]$} & 0.98 \\
\hline Demonstrate $\mathrm{ScvO}_{2} \geq 70 \%$ & Shock despite fluids ${ }^{c}$ & 7,854 & 0.94 & 0.24 & 0.98 & {$[0.86,1.10]$} & 0.69 \\
\hline Achieve low plateau pressure control & Mechanical ventilation $^{\mathrm{d}}$ & 7,860 & 0.67 & $<0.0001$ & 0.70 & {$[0.62,0.78]$} & $<0.0001$ \\
\hline
\end{tabular}

a Model fit statistics: $C=22.2$ with $18 d f, P=0.22$, log-likelihood $R^{2} 28.1 \%$, a $\chi^{2}$ dispersion of 1.05

b Model fit statistics: $C=28.7$ with $18 d f, P=0.053$, log-likelihood $R^{2} 20.5 \%$, a $\chi^{2}$ dispersion of 1.08

c Model fit statistics: $C=24.3$ with $18 \mathrm{df}, P=0.15$, $\log$-likelihood $R^{2} 11.4 \%$, a $\chi^{2}$ dispersion of 1.00

${ }^{d}$ Model fit statistics: $C=6.61$ with $18 \mathrm{df}, P=0.99$, log-likelihood $R^{2} 27.0 \%$, a $\chi^{2}$ dispersion of 1.06

mortality. Therefore, attention to adjustment for severity of patient illness at time of enrollment should be attempted.

Similarly, failure to achieve blood glucose control despite attempting to do so is not the same as failure to make the attempt. Attempting to discriminate failure to achieve a target versus patient responsiveness adds a layer of complexity and subjectivity to the scoring process that would be difficult to validate. Nevertheless, because patient responsiveness is unlikely to change over time, the scoring should reflect each hospital's improvement attempts. By combining a number of elements in the care bundles, the Campaign sought to maximize outcome improvement. At the same time, such an approach compromises measuring the effect of individual elements.

The fact that performance improvement studies are susceptible to general trends in the change in mortality and clinical practice patterns over time is another potential limitation of the study, but the variable start times for each site established that such effects were unlikely to explain the improvement in mortality. The baseline mortality rate for sites entering at variable times throughout the 2-year study period did not change. Formal severity scores were not obtained for patients entered into the database due to limited personnel resources in the absence of external site funding and confidentiality concerns. Therefore, decreasing mortality seen over the 2 year initiative might be explained by the enrollment of less severely ill patients over time, in spite of the static baseline center mortality. To control for entry of less severely ill patients in the database over time as the reason for decreasing mortality, severity was assessed based on variables linked to patient mortality that were available in the database (Table 4). When mortality was adjusted accordingly, although the magnitude of the effect was slightly reduced, it remained statistically significant.
In conclusion, the results of this study demonstrate that the use of a multifaceted performance improvement initiative was successful in changing sepsis treatment behavior as evidenced by a significant increase in compliance with sepsis performance measures. This compliance was associated with a significant reduction in hospital mortality in patients with severe sepsis and septic shock over the duration of the 2-year study, but the study design does not allow us to say, with certainty, whether this was due to some or all bundle elements, increased awareness of severe sepsis, or other unrelated factors. Many unanswered questions remain that could provide direction for future research, including the mortality trend in hospitals that have not implemented the bundles, and confirmation of which components of the bundles reduce mortality. These results are consistent with an earlier report from Spain [38], and extend the findings of that study by suggesting that the improvement in achievement of bundle targets and association with improved outcome is sustained over time and is demonstrated across a wide number of countries and settings. Professional societies frequently generate evidence-based clinical practice guidelines, but efforts to disseminate such guidelines have rarely been of a scale comparable to this Campaign. The results of this study should encourage similar efforts to implement guidelines as a means to improve outcomes.

Acknowledgments The authors gratefully acknowledge the dedication and efforts of Deb McBride during the Campaign and in the development of this manuscript. We also acknowledge the individuals leading the effort at participating sites who made all of this happen as volunteers who believed in the Campaign and what we were trying to accomplish as their sole motivation. The work was supported by Eli Lilly and Co., Edwards Lifesciences, Philips Medical Systems, the Society of Critical Care Medicine, and European Society of Intensive Care Medicine.

Dr. Levy has received grants from Eli Lilly \& Co and Philips Medical Systems. Dr. Marshall has consultancies with Eisai, Eli 
Lilly, Specter Diagnostics, Bayer, Artisan, and Leo Pharma. Dr. Artigas has received grants from Eli Lilly. Dr. Beale has disclosed payment from multiple sources that were paid to his department and institution (details on file with the editorial office). Drs. Reihart and Silva have consultancies with Eli Lilly. Dr. Angus has participation in DSMB, Prowess-Shock, and Eli Lilly. The remaining authors have not disclosed any potential conflicts of interest.

\section{References}

1. Angus DC, Linde-Zwirble WT, Lidicker J, Clermont G, Carcillo J, Pinsky MR (2001) Epidemiology of severe sepsis in the United States: analysis of incidence, outcome, and associated costs of care. Crit Care Med 29:1303-1310

2. Martin GS, Mannino DM, Eaton S, Moss M (2003) The epidemiology of sepsis in the United States from 19792000. N Engl J Med 348:1546-1554

3. Rivers E, Nguyen B, Havstad S, Ressler J, Muzzin A, Knoblich B, Peterson E, Tomlanovich M, Early Goal-Directed Therapy Collaborative Group (2001) Early goal directed therapy in the treatment of severe sepsis and septic shock. N Engl J Med 345:1368-1377

4. Annane D, Sébille V, Charpentier C, Bollaert PE, François B, Korach JM, Capellier G, Cohen Y, Azoulay E, Troché G, Chaumet-Riffaud P, Bellissant E (2002) Effect of treatment with low doses of hydrocortisone and fludricortisone on mortality in patients with septic shock. JAMA 288:862-871

5. Bernard GR, Vincent JL, Laterre PF LaRosa SP, Dhainaut JF, LopezRodriguez A, Steingrub JS, Garber GE, Helterbrand JD, Ely EW, Fisher CJ Jr, Recombinant human protein $\mathrm{C}$ Worldwide Evaluation in Severe Sepsis (PROWESS) study group (2001) Efficacy and safety of recombinan human activated protein $\mathrm{C}$ for severe sepsis. N Engl J Med 344:699-709

6. van den Berghe $G$, Wouters P, Weekers F, Verwaest C, Bruyninckx F, Schetz M, Vlasselaers D, Ferdinande P, Lauwers P, Bouillon R (2001) Intensive insulin therapy in critically ill patients. N Engl J Med 345:1359-1367

7. The Acute Respiratory Distress Syndrome Network (2000) Ventilation with lower tidal volumes as compared with traditional tidal volumes for acute lung injury and the acute respiratory distress syndrome. N Engl J Med 342:1301-1308

8. Kress JP, Pohlman AS, O'Connor MF, Hall JB (2000) Daily interruption of sedative infusions in critically ill patients undergoing mechanical ventilation. N Engl J Med 342:14711477
9. Ely EW, Baker AM, Dunagan DP, Burke HL, Smith AC, Kelly PT, Johnson MM, Browder RW, Bowton DL, Haponik EF (1996) Effect on the duration of mechanical ventilation of identifying patients capable of breathing spontaneously. N Engl J Med 335:1864-1869

10. Bellomo R, Chapman M, Finfer S, Hickling K, Myburgh J (2000) Lowdose dopamine in patients with early renal dysfunction: a placebo-controlled randomised trial. Australian and New Zealand intensive care society (ANZICS) clinical trials group. Lancet 356:2139-2143

11. Townsend SR, Schorr C, Levy MM, Dellinger RP (2008) Reducing mortality in severe sepsis: The Surviving Sepsis Campaign. Clin Chest Med 29:721-733

12. Dellinger RP, Carlet JM, Masur H, Gerlach H, Calandra T, Cohen J, GeaBanacloche J, Keh D, Marshall JC, Parker MM, Ramsay G, Zimmerman JL, Vincent JL, Levy MM, Surviving Sepsis Campaign Management

Guidelines Committee (2004) Surviving Sepsis Campaign guidelines for management of severe sepsis and septic shock. Crit Care Med 32:858873

13. Dellinger RP, Levy MM, Carlet JM, Bion J, Parker MM, Jaeschke R, Reinhart K, Angus DC, Brun-Buisson C, Beale R, Calandra T, Dhainaut JF, Gerlach H, Harvey M, Marini JJ, Marshall J, Ranieri M, Ramsay G, Sevransky J, Thompson BT, Townsend S, Vender JS, Zimmerman JL, Vincent JL (2008) Surviving Sepsis Campaign: international guidelines for management of severe sepsis and septic shock: 2008. Intensive Care Med 34:17-60, erratum 34:783-785

14. Surviving Sepsis Campaign implementation and the appropriate role of industry.

http://www.survivingsepsis.org/ About_the_Campaign/Documents/ Industry_20Fact_20Sheet_200320062 .pdf. Accessed 5 Dec 2009

15. Cabana MD, Rand CS, Powe NR, Wu AW, Wilson MH, Abboud PA, Rubin HR (1999) Why don't physicians follow clinical practice guidelines? A framework for improvement. JAMA 282:1458-1465
16. Sinuff T, Eva KW, Meade M, Dodek P, Heyland D, Cook D (2007) Clinical practice guidelines in the intensive care unit: a survey of Canadian clinicians' attitudes. Can J Anaesth 54:728-736

17. Cook DJ, Meade MO, Hand LE, McMullin JP (2002) Toward understanding evidence uptake: semirecumbency for pneumonia prevention. Crit Care Med 30:14721477

18. Sinuff T, Kahnamoui K, Cook DJ, Giacomini M (2007) Practice guidelines as multipurpose tools: a qualitative study of noninvasive ventilation. Crit Care Med 35:776-782

19. Sinuff T, Muscedere J, Cook D, Dodek P, Heyland D (2008) Canadian Critical Care Trials Group. Ventilatorassociated pneumonia: improving outcomes through guideline implementation. J Crit Care 23:118125

20. Sinuff T, Cook D, Giacomini M, Heyland D, Dodek P (2007) Facilitating clinician adherence to guidelines in the intensive care unit: a multicenter, qualitative study. Crit Care Med 35:2083-2089

21. Pronovost PJ, Berenholtz SM, Needham DM (2008) Translating evidence into practice: a model for large scale knowledge translation. BMJ 337:963965

22. Vandijck DM, Labeau SO, Blot SI (2008) Facilitating clinician adherence to guidelines in the intensive care unit. Crit Care Med 36:655

23. Berwick DM (2008) The science of improvement. JAMA 299:1182-1184

24. Amalberti R, Auroy Y, Berwick D, Barach P (2005) Five system barriers to achieving ultrasafe health care. Ann Intern Med 142:756-764

25. Levy MM, Pronovost PJ, Dellinger RP, Townsend SR, Resar RK, Clemmer TP, Ramsay G (2004) Sepsis change bundles: converting guidelines into meaningful change in behavior and clinical outcome. Crit Care Med 32(suppl):S595-S597

26. Resar R, Pronovost P, Haraden $C$ Simmonds T, Rainey T, Nolan T (2005) Using a bundle approach to improve ventilator care processes and reduce ventilator-associated pneumonia. Jt Comm J Qual Patient Saf 31:243-248 
27. Severe sepsis bundles. Resuscitation bundle. http://www.survivingsepsis. org/Bundles/Pages/default.aspx.

Accessed 5 Dec 2009

28. Severe sepsis bundles. Management bundle. http://www.survivingsepsis. org/Bundles/Pages/default.aspx. Accessed 5 Dec 2009

29. Levy MM, Fink MP, Marshall JC, Abraham E, Angus D, Cook D, Cohen J, Opal SM, Vincent JL, Ramsay G; SCCM/ESICM/ACCP/ATS/SIS (2003) $2001 \mathrm{SCCM} / \mathrm{ESICM} / \mathrm{ACCP} / \mathrm{ATS} / \mathrm{SIS}$ international sepsis definitions conference. Crit Care Med 31:1250-1256

30. Townsend S, Dellinger RP, Levy MM, Ramsay G (eds) (2005) Implementing the Surviving Sepsis Campaign. Society of Critical Care Medicine, Mount Prospect

31. http://www.hhs.gov/ohrp/qualityfaq. html. Accessed 12 Aug 2009

32. Pronovost P, Needham D, Berenholtz S, Sinopoli D, Chu H, Cosgrove S, Sexton B, Hyzy R, Welsh R, Roth G, Bander J, Kepros J, Goeschel C (2006) An intervention to decrease catheter-related bloodstream infections in the ICU. N Engl J Med 355:2725-2732
33. Shapiro NI, Howell MD, Talmor D, Lahey D, Ngo L, Buras J, Wolfe RE, Weiss JW, Lisbon A (2006) Implementation and outcomes of the Multiple Urgent Sepsis Therapies (MUST) protocol. Crit Care Med 34:1025-1032

34. El Solh AA, Akinnusi ME, Alsawalha LN, Pineda LA (2008) Outcome of septic shock in older adults after implementation of the sepsis "bundle". J Am Geriatr Soc 56:272-278

35. Nguyen HB, Corbett SW, Steele R, Banta J, Clark RT, Hayes SR, Edwards J, Cho TW, Wittlake WA (2007) Implementation of a bundle of quality indicators for the early management of severe sepsis and septic shock is associated with decreased mortality. Crit Care Med 35:1105-1112
36. Kumar A, Roberts D, Wood KE, Light B, Parrillo JE, Sharma S, Suppes R, Feinstein D, Zanotti S, Taiberg L, Gurka D, Kumar A, Cheang M (2006) Duration of hypotension before initiation of effective antimicrobial therapy is the critical determinant of survival in human septic shock. Crit Care Med 34:1589-1596

37. The NICE-SUGAR Study Investigators (2009) Intensive versus conventional glucose control in critically ill patients. N Engl J Med 360:1283-1297

38. Ferrer R, Artigas A, Levy MM, Blanco J, González-Díaz G, Garnacho-Montero J, Ibáñez J, Palencia E, Quintana M, de la Torre-Prados MV, Edusepsis Study Group (2008) Improvement in process of care and outcome after a multicenter severe sepsis educational program in Spain. JAMA 299:2294-2303 